\title{
Human Immunodeficiency Virus 2
}

National Cancer Institute

\section{Source}

National Cancer Institute. Human Immunodeficiency Virus 2. NCI Thesaurus. Code

C14221.

Any viral organism that can be assigned to the species Human Immunodeficiency virus 2 . 